\title{
The bone-protective effect of a Taiwanese yam (Dioscorea alata L. Cv. Tainung No. 2) in ovariectomised female BALB/C mice
}

\author{
Hsiao-ling Chen, ${ }^{a * \dagger}$ Ling-tiao Hong, ${ }^{a}$ Jong Kang Lee ${ }^{b}$ \\ and Ching-jang Huang ${ }^{c t}$
}

\begin{abstract}
BACKGROUND: Yam products have been marketed for treating postmenopausal syndromes. This study investigated the effects of Dioscorea alata L. cv. Tainung No. 2 (TNG yam) on the bone density of ovariectomised (OVX) female BALB/c mice and the mechanism whereby TNG yam exerted this effect. Sham and OVX control groups were fed a control diet while remaining OVX mice were randomly allocated into experimental diets, i.e. yam (630 g TNG powder kg $\left.{ }^{-1}\right)$, E2 (20 mg $17 \beta$-oestradiol kg $^{-1}$ ), or genistein ( $2 \mathrm{~g}_{\text {genistein }} \mathrm{kg}^{-1}$ ) diet. After 12 weeks of feeding, the uterine weight, indices of bone mass and caecal short chain fatty acids were determined.

RESULTS: Neither a yam nor genistein diet restored the OVX-induced uterine atrophy as did the E2 diet. The femoral and lumbar bone mineral density (BMD) of mice fed the yam diet was greater than those of the sham group, respectively $(P<0.05$ vs 0 VX control), while the lumbar BMD of yam and sham groups were similar ( $P>0.05$ vs sham). The femoral ash and calcium content in the yam group was significantly greater than that in the OVX control group, respectively $(P<0.05$ vs OVX control). The total short chain fatty acid content in the caecum, only enhanced in the yam group, was not correlated with the calcium content of either bone or the plasma calcium level.
\end{abstract}

CONCLUSION: TNG yam prevented loss of BMD and improved bone calcium status without stimulating uterine hypertrophy in OVX BALB/c mice. TNG yam may be beneficial for postmenopausal women for preventing bone loss.

(C) 2008 Society of Chemical Industry

Keywords: ovariectomised; Dioscorea alata; yam; genistein; bone mineral density; calcium; short chain fatty acid

\section{INTRODUCTION}

Yam is the common name of rhizomes of a perennial plant from the genus Dioscorea in the family Dioscoreaceae. It is estimated that there are more than 600 species of yams in the world, 14 of which are found in Taiwan. ${ }^{1}$ There are five major cultivated species of Taiwanese yam: D. alata, D. batatas, D. japonica, D. alata L. var purpurea, and $D$. doryophora. Among these, D. alata cv. Tainung No. 2 (TNG) is one of the most consumed varieties. ${ }^{1}$

Most of the worldwide production of yam is located in Africa where yam has been traditionally used as a staple food. In addition, yam has been widely used for the enhancement of health in oriental countries and traditionally considered as a superior Chinese herb to improve gastrointestinal function. ${ }^{2}$ Recently, Wang et al. ${ }^{3}$ have demonstrated that yam-rich diets enhance caecal fermentation and proliferation of bifidobacteria. Yams have also been implicated in the promotion of the health of postmenopausal women. The wild Mexican yam has been marketed for treating postmenopausal syndromes. Wu et al. ${ }^{4}$ demonstrate that replacing two-thirds of staple food with Taiwanese yam (D. alata) in postmenopausal women for 30 days improves the status of sex hormones, which suggests that D. alata may contain phytoestrogenic compounds. Recently, Cheng et al. ${ }^{5}$ identified five phytoestrogenic compounds, $\gamma$ - tocopherol-9, coenzyme Q9, 1-feruloylglycerol, $\alpha$-tocopherol and hydro-Q9 chromene, in TNG yam based on the ligand-dependent transactivation assay of oestrogen receptors, which further supports the phytoestrogenic potential of TNG yams.

Ovarian hormone deficiency is a major risk factor for osteoporosis in postmenopausal women. ${ }^{6}$ Hormone replacement therapy (HRT) effectively alleviates postmenopausal symptoms and lowers the risk for coronary heart disease and osteoporosis. However, a longitudinal study indicates more than $80 \%$ of $45-55$-year-old women are unwilling to be placed on this therapy, either be-

\footnotetext{
Correspondence to: Hsiao-ling Chen, School of Nutrition, Institute of Nutritional Science, Chung Shan Medical University, No. 110, Sec. 1 Chien-Kuo N. Rd, Taichung 402, Taiwan.E-mail: hlchen@csmu.edu.tw

† Both authors contributed equally.

a School of Nutrition, Institute of Nutritional Science, Chung Shan Medical University, Taichung, Taiwan

b Nuclear Medicine Department, Chung Shan Medical University Hospital, Taichung, Taiwan

c Department of Biochemical Science and Technology, Institute of Microbiology and Biochemistry, National Taiwan University, Taichung, Taiwan
} 
cause of the concern of increased risk of certain types of cancer or contraindications. ${ }^{7}$ Phytoestrogens, plant-derived compounds that can interact with oestrogen receptors and exhibit oestrogenic activities, ${ }^{8}$ have been considered an alternative remedy for HRT. Soy isoflavones, a group of well-known phytoestrogens, have been shown to exert protective potential against bone loss in several animal and tissue studies. ${ }^{9,10}$ Epidemiological studies also generally suggest a positive association between soy consumption and bone mineral density. ${ }^{11}$ In addition, resistant starch has been shown to enhance calcium absorption probably by enhancing colonic fermentation. ${ }^{12,13}$ TNG yam, sources of potential phytoestrognes and resistant starch, ${ }^{3}$ may protect against bone loss in postmenopausal women both through the direct phytoestrogenic action on tissues and the enhancing effect on calcium absorption.

To examine the bone-protective potency of TNG yam, we fed ovariectomised (OVX) BALB/c mice with a yam diet for 12 weeks, and compared the effect of yam with those of $17 \beta$-oestradiol (E2) and genistein, a soy phytoestrogen, on bone mineral density (BMD), ash and calcium contents, as well as serum calcium level. Colonic short chain fatty acids were determined to explore whether the fermentation of yam contributed to the bone-protective role of yam.

\section{MATERIALS AND METHODS}

\section{Preparation and analysis of yam powder}

Dioscorea alata L. cv. Tainung No. 2 (TNG) was purchased from its major production area (Farmer's Association, Nantao County, Taiwan). The whole yam tubers were peeled, steamed, lyophilised, and milled to powder. The protein, fat, ash, calcium, magnesium and phosphorus content of the lyophilised yam powder and corn starch were analysed according to the standards of the Association of Official Analytical Chemists (AOAC) methods. ${ }^{14}$ Protein level was determined by Kjeldahl analysis for nitrogen concentration. ${ }^{14}$ Fat was extracted by using ether in a Soxhlet apparatus. ${ }^{14}$ Ash was determined by heating at $550{ }^{\circ} \mathrm{C}$ overnight. ${ }^{14}$ Moisture level was determined by vacuum drying at $110^{\circ} \mathrm{C}$ overnight. ${ }^{14}$ The mineral content was determined using an atomic absorption spectrometer (PE3300; Perkin-Elmer, Norwalk, CT, USA). Dietary fibre contents were analysed using enzymatic-gravimetric method. ${ }^{12}$ Resistant starch was analysed according to the AOAC method with a commercial kit (RSTAR11/02; Megazyme, Bray, Ireland). ${ }^{15}$ The carbohydrate level was calculated by subtracting protein, fat, ash, dietary fibre and moisture levels (Table 1).

\section{Experimental design}

Female BALB/c mice (4 weeks old) were obtained from the National Laboratory Animal Breeding and Research Center (Taipei, Taiwan). They were housed individually in solid-bottomed plastic cages with wood shavings for bedding, in a room maintained on a 12-h light/12-h dark cycle (0800-2000), at $24 \pm 1{ }^{\circ} \mathrm{C}$ and $50 \%$ humidity. All animals were allowed free access to water and food during the study. Animal care followed the guidelines of the National Research Council $^{16}$ and was approved by the Institutional Animal Care and Use Committee in the Chung Shan Medical University. Mice were initially fed a standard non-purified diet (Rodent Laboratory Chow; Purina Mills, St Louis, MO, USA) until they were undergone sham or OVX surgery at 8 weeks of age. Three days later, OVX mice were assigned randomly to consume control (modified corn oil AIN-93 diet), yam (630 g TNG powder kg ${ }^{-1}$ diet), oestradiol-supplemented (2 mg $17 \beta$-oestradiol $\mathrm{kg}^{-1}$ diet; Sigma, St Louis, MO, USA), or genistein-supplemented ( $0.2 \mathrm{~g}$ genistein $\mathrm{kg}^{-1}$ diet; Sigma) diets
Table 1. Composition of the corn starch and lyophilised cooked yam powder prepared from skinned yam tuber ${ }^{a}$

\begin{tabular}{lcc|} 
Major component $\left(\mathrm{g} \mathrm{kg}^{-1}\right)$ & Corn starch & Yam powder \\
\hline Carbohydrate & $874.5 \pm 0.6$ & $722.7 \pm 0.6$ \\
Resistant starch & 0 & $150.8 \pm 22.3$ \\
Protein & 0 & $145.8 \pm 0.5$ \\
Fat & 0 & $04.6 \pm 0.1$ \\
Ash & $0.4 \pm 0.1$ & $40.4 \pm 0.1$ \\
Total dietary fibre & 0 & $5.30 \pm 0.02$ \\
Moisture & $125.1 \pm 0.5$ & $68.9 \pm 3.0$ \\
Ca $\left(10^{-3}\right)$ & $297.0 \pm 4.0$ & $132.4 \pm 4.0$ \\
$\mathrm{P}\left(10^{-3}\right)$ & $68.2 \pm 6.0$ & $2398.0 \pm 12.0$ \\
$\mathrm{Mg}\left(10^{-3}\right)$ & $60.8 \pm 3.0$ & $557.2 \pm 31.0$ \\
\hline a Data are means \pm SD of three replicates. \\
\hline
\end{tabular}

Table 2. Nutrient content and nutritional values of the control and yam diets

\begin{tabular}{lrr|} 
Parameter & Control & Yam \\
\hline Nutrient content $\left(\mathrm{g} \mathrm{kg}^{-1}\right)$ & & \\
Carbohydrate & 549.9 & 360.3 \\
Resistant starch & 0.0 & 94.6 \\
Protein & 200.0 & 291.8 \\
Fat & 70.0 & 72.9 \\
Dietary fibre & 50.0 & 83.4 \\
Ca & 5.2 & 5.1 \\
P & 2.0 & 3.5 \\
M & 0.5 & 0.8 \\
Energy density ${ }^{\mathrm{b}}$ (kcal g $^{-1}$ ) & 3.6 & 3.3 \\
Energy (\%) & & \\
Carbohydrate & 60.6 & 44.2 \\
Protein & 22.0 & 35.8 \\
Fat & 17.4 & 20.1 \\
\hline a Resistant starch is not included. & \\
b Energy from resistant starch is not included for the energy calculation. \\
\hline
\end{tabular}

for 12 weeks, while the sham group was fed the control diet. The dose of genistein used in the study followed the study by Ward et al. ${ }^{17}$ while the dose of $17 \beta$-oestradiol in the diet was based on the relative binding affinity of genistein and $17 \beta$-oestradiol to the oestrogen receptor- $\alpha .^{8}$ The composition (in $\mathrm{g} \mathrm{kg}^{-1}$ ) of control diet was corn starch, 629.5; corn oil, 70; casein, 200; cellulose, 50; mineral mix, 35; vitamin 10; L-cystine, 3; and choline bitartrate, 2.5. All diets contained corn oil instead of soy oil, to eliminate any additional dietary soy isoflavones. Since yam tuber is starchy and can be consumed as a staple, we replaced corn starch directly with TNG. The weight of genistein also partially replaced the corn starch. The nutritional values of control and yam diets were shown in Table 2. The body weights of mice were measured twice a week while food intake was monitored every day. Mice were decapitated after 12 weeks of study without fasting. Blood was collected into heparinised tubes, while both the femur and the lumbar bones (L3-5) were dissected for further analysis. Caecal contents were removed, weighed, and stored at $-80^{\circ} \mathrm{C}$ for further analyses of short chain fatty acid (SCFA). 
Radiographic analysis of the femur and lumbar bones

The bone densities $\left(\mathrm{g} \mathrm{cm}^{-2}\right)$ of the femur and lumbar bones were measured by a dual-energy X-ray absorptiometry (Lunar Expert$\mathrm{XL}$, version 1.8; Lunar-Norland Medical Systems, Madison,WI, USA) in triplicate. The speed of scan was $3 \mathrm{~cm} \mathrm{~s}^{-1}$; with a resolution of $0.6 \mathrm{~mm}$. The coefficient of variation for the femur and lumbar bone was $2.5 \%$ and $5 \%$, respectively.

\section{Histology of femoral cross-sections}

In a pilot study, we found OVX caused bone loss mainly in the region close to distal metaphysis of the femur. Therefore, a crosssection of the femur was prepared at this region. After being decalcified in ethylenediaminetetraacetic acid (EDTA, $30 \mathrm{~g} \mathrm{~L}^{-1}$ ) phosphate buffer $\left(0.1 \mathrm{~mol} \mathrm{~L}^{-1}, \mathrm{pH}\right.$ 7.4) overnight, the right femur was embedded in tissue freezing medium (Leica Microsystems Nusslich GmbH, Wetzlar, Germany) for cryosection (Leica CM3050S; Bartels and Stout Inc., Issaquah, WA, USA). The section (5 mm) was stained with haemotoxylin (Merck, Darmstadt, Germany) and observed under a light microscope (E600; Nikon Corp., Tokyo, Japan). The thickness of the cortical bone and the trabecular bone fraction (trabecular bone volume in a cube/total volume of a cube) ${ }^{18}$ was quantified using Image Analysis Systems, (Lucia Measurement version 4.81; Laboratory Imaging Ltd., Praha, Czech Republic).

\section{Bone ash and calcium contents}

The ash contents of the femur and lumbar bones were measured according to the AOAC method. ${ }^{14}$ The ash was weighed and then diluted with nitric acid (atomic absorption spectrometergrade). The calcium concentration was determined with an atomic absorption spectrometer (PE3300; Perkin-Elmer).

\section{Plasma calcium concentration}

Plasma calcium was measured with a commercial kit (CA590-592; Randox, Antrim, UK) according to the protocol provided by the manufacturer. The plasma calcium concentration was calculated by comparison with appropriate standards.

\section{Caecal short chain fatty acids}

The caecal content was analysed for acetate, propionate and $n$ butyrate with 4-methyl- $n$-valeric acid as an internal standard, as described previously. ${ }^{19,20}$ SCFAs extracted from caecal contents were dissolved in a phosphate solution $\left(100 \mathrm{~g} \mathrm{~L}^{-1}\right)$ just before they were injected onto a gas chromatography (GC-14B; Shimadzu, Tokyo, Japan) fitted with a glass capillary column $(0.25 \mathrm{~mm} \times 30 \mathrm{~m}$, Stabilwax-DA; Restek Corp., Bellefonte, PA, USA) and a flame ionisation detector. The initial oven temperature was $100^{\circ} \mathrm{C}$ and was raised to $200^{\circ} \mathrm{C}$ at $6^{\circ} \mathrm{C} \mathrm{min}^{-1}$. The temperature of the injection port and detector was $250^{\circ} \mathrm{C}$, respectively. The flow rate of carrier gas, $\mathrm{N}_{2}$, was adjusted to be $1 \mathrm{~mL} \mathrm{~min}^{-1}$. Peak areas were analysed with C-R6A Chromatopac (Shimadzu Corp.). Caecal SCFA content (mmol) was calculated as the SCFA concentration $\left(\mathrm{mmol} \mathrm{g} \mathrm{g}^{-1}\right.$ caecal content) $\times$ caecal content mass $(g)$ at the time of sacrifice.

\section{Statistical analysis}

The Statistical Package for Social Science (SPSS for Windows, version 8.0; SPSS Inc., Chicago, IL, USA) was used for statistical analysis. Values are presented as means with standard deviation. One-way ANOVA tests were used to determine the significance of differences among groups. The group-wise comparison was performed by Duncan's multiple range test. ${ }^{21}$ The correlation between caecal SCFA content ( $\mathrm{mmol}$ caecum ${ }^{-1}$ ) and femur, lumbar calcium content (mg), blood calcium level was determined by Pearson's correlation test. ${ }^{21}$ Effects were considered significant at $P<0.05$.

\section{RESULTS \\ Body weight and feed intake}

Compared to the sham-operated group, the OVX control mice did not differ in weight gain, feed intake and feed efficiency $(P>0.05$, Table 3). Supplementation with oestradiol tended to reduce the weight gain and food intake as compared to the OVX control. Despite that, the yam group consumed the greatest amount of diet as compared to all other OVX groups $(P<0.05)$, the feed efficiency was similar among all five groups $(P<0.05$, Table 3$)$. The daily calcium intake of sham, control, yam, oestradiol and genistein groups was $18.18 \pm 1.08,17.27 \pm 1.14,19.16 \pm 1.27$, $16.60 \pm 1.30$ and $17.01 \pm 1.40 \mathrm{mg}$, respectively, after the daily feed intake was taken into account.

\section{Uterus weight}

The uterus weight was significantly lower in the OVX control group, $22.4 \pm 15.1 \mathrm{mg}$, than in the sham group, $102.1 \pm 52.6 \mathrm{mg}$ $(P<0.05)$. Supplementation with oestradiol effectively prevented the uterine atrophy of OVX; the uterus weight of the E2 group $(139.5 \pm 38.4 \mathrm{mg})(P<0.05$ vs OVX control) was comparable to that of the sham group ( $P>0.05$ vs sham). Neither the yam nor the genistein diet reversed the atrophy caused by OVX. The uterus weight in the yam and genistein groups was $22.0 \pm 21.3 \mathrm{mg}$ and $21.5 \pm 9.5 \mathrm{mg}$, respectively ( $P>0.05$ vs OVX control group).

\section{Bone mineral density}

The BMD of femur in the OVX group, $0.109 \pm 0.011 \mathrm{~g} \mathrm{~cm}^{-2}$, was significantly lower than that in the sham group, $0.079 \pm$ $0.015 \mathrm{~g} \mathrm{~cm}^{-2}(P<0.05$ vs sham) (Fig. 1A). OVX mice with oestradiol supplement had similar femoral BMD to sham-operated mice while mice in the yam or genistein group had greater BMD than the OVX control group ( $P<0.05$ vs OVX control). Similarly, the BMD of lumbar bones were lower in the OVX group as compared with the sham group ( $P<0.05$ vs sham). Mice fed the yam, oestradiol or genistein diet had similar BMD to the sham-operated mice $(P>0.05$ vs sham $)$.

Table 3. Body weight, feed intake and feed efficiency of shamoperated or ovariectomised BALB/c mice fed control, yam, oestradiol or genistein diets for 12 weeks

\begin{tabular}{|lccc|} 
Group & Weight gain (g) & $\begin{array}{c}\text { Feed intake } \\
\left(\mathrm{g} \mathrm{day}^{-1}\right)\end{array}$ & $\begin{array}{c}\text { Feed efficiency } \\
\left(10^{-2}\right)\end{array}$ \\
\hline Sham-operated & $6.7 \pm 1.6^{\mathrm{ab}}$ & $3.5 \pm 0.2^{\mathrm{bc}}$ & $2.2 \pm 0.7$ \\
Control & $6.7 \pm 2.5^{\mathrm{ab}}$ & $3.3 \pm 0.2^{\mathrm{ab}}$ & $2.5 \pm 0.7$ \\
Yam & $7.6 \pm 1.7^{\mathrm{b}}$ & $3.8 \pm 0.2^{\mathrm{c}}$ & $2.3 \pm 0.5$ \\
Oestradiol & $5.0 \pm 0.8^{\mathrm{a}}$ & $3.2 \pm 0.2^{\mathrm{a}}$ & $2.0 \pm 0.5$ \\
Genistein & $6.7 \pm 2.5^{\mathrm{ab}}$ & $3.3 \pm 0.3^{\mathrm{ab}}$ & $2.5 \pm 0.6$ \\
\hline
\end{tabular}

Results are expressed as means \pm SD $(n=10-14)$. Different superscript letters denote significant differences between groups as analysed by one-way ANOVA followed by Duncan's multiple test.

Feed efficiency $=$ daily body weight/daily feed intake. No significant difference in feed efficiency was found between groups as analysed by Duncan's multiple range test. 

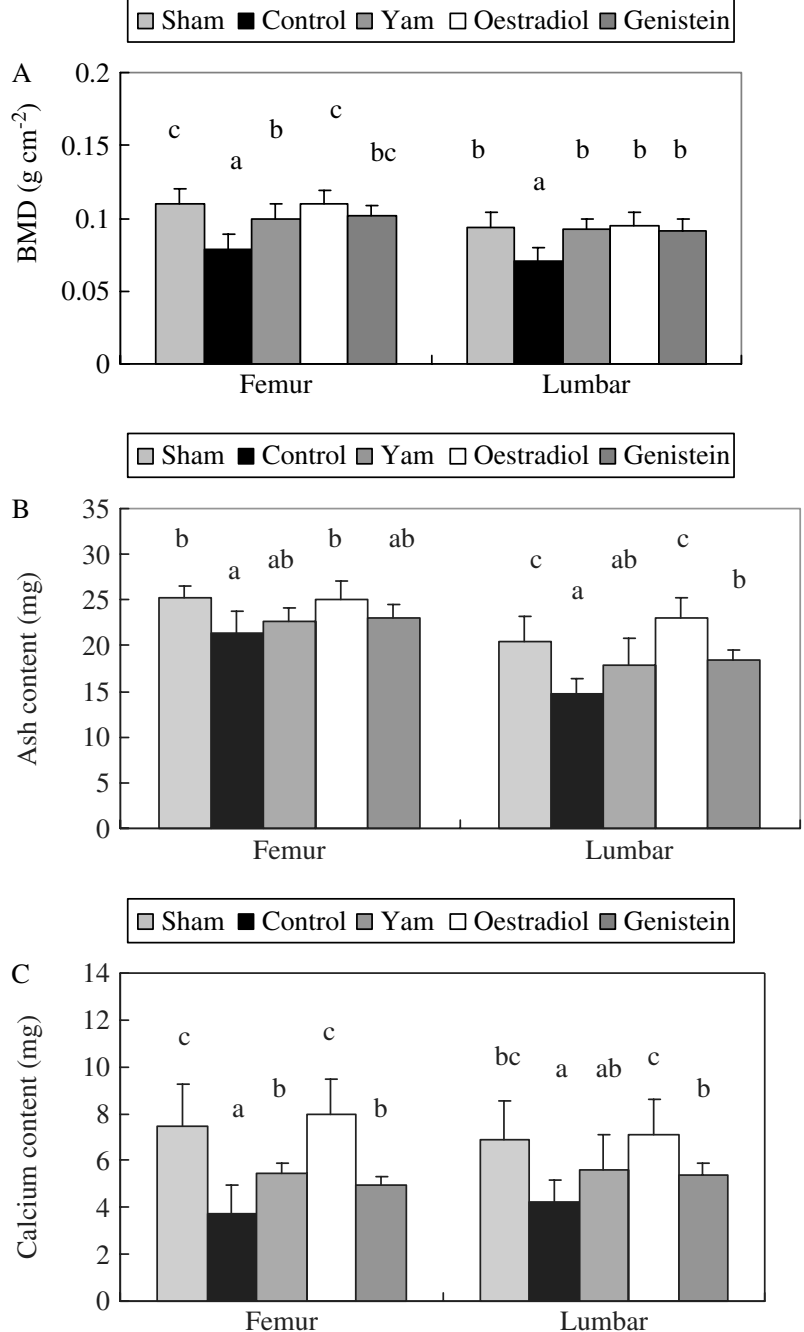

Figure 1. (A) Bone mineral density (BMD), (B) ash content, and (C) calcium content of femur and lumbar bones of the sham group fed the control diet (Sham) and ovariectomised BALB/c mice fed either a control (Control), yam (Yam), oestradiol-supplemented or genistein-supplemented diet. Data are expressed as mean \pm SD ( $n=8-11$ animals per group). Different superscript letters denote significant differences across groups as analysed by Duncan's multiple test $(P<0.05)$.

\section{Ash content of femur and lumbar bones}

The femoral ash content (mg) of OVX group was 15\% lower than that in the sham group ( $P<0.05$ vs sham). The bone ash in the yam and genistein groups was not different to that in the sham group ( $P>0.05$ vs sham) (Fig. 1B). The ash contents of lumbar bones were significantly lowered by $\sim 26 \%$ in the OVX control group as compared to the sham group ( $P<0.05$ vs sham). This lumbar ash content was greater in the oestradiol and genistein groups as compared to the control group, respectively $(P<0.05$ vs control).

\section{Calcium content of femur and lumbar bones}

There was a significantly lower femoral calcium content in OVX mice as compared to the sham-operated mice $(P<0.05$ vs sham) (Fig. 1C). The femoral calcium content in mice fed yam and genistein diets was $\sim 73 \%$ ( $P<0.05$ vs OVX control) and $\sim 67 \%$ $(P<0.05$ vs $\mathrm{OVX}$ control) of that in the sham group, respectively, while the oestradiol supplement fully preserved the bone calcium
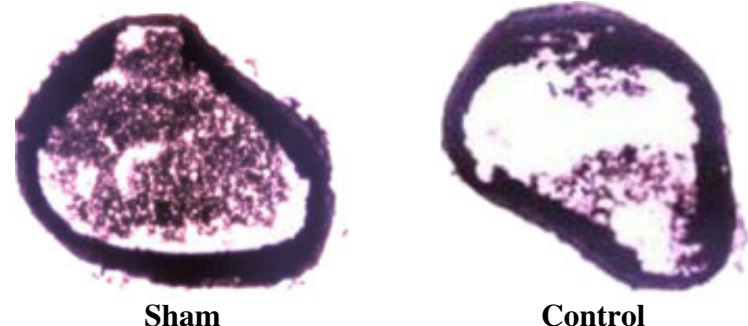

Control

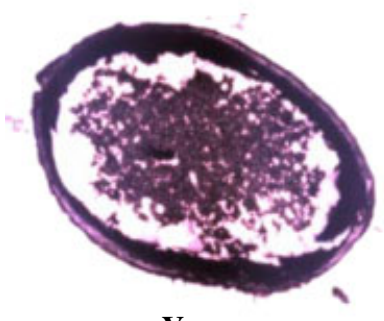

Yam

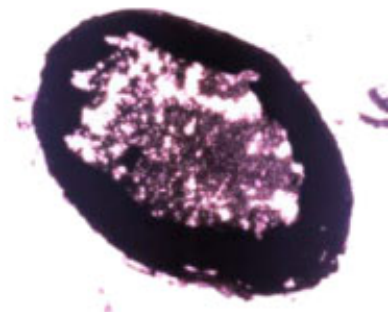

Oestradiol

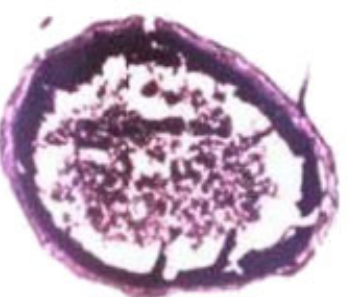

Genistein
$1 \mathrm{~mm}$
Figure 2. The cross-section of femur stained with haematoxylin (magnification, H28) in the sham group fed the control diet (Sham), and in ovariectomised BALB/c mice fed either the control diet (Control), yam diet (Yam) or the diet supplemented with oestradiol or genistein.

content ( $P>0.05$ vs sham). In terms of lumbar bones, the calcium content in the OVX, yam and genistein group was $\sim 61 \%(P<0.05$ vs sham), $\sim 81 \%$ ( $P>0.05$ vs sham $)$ and $\sim 78 \%(P>0.05$ vs sham) of that in the sham-operated mice, respectively, while the E2 supplement fully preserve the calcium content $(P>0.05$ vs sham).

\section{Femoral cross-sections}

The stained femoral sections are shown in Fig. 2. The thickness of cortical bone was $0.24 \pm 0.05,0.25 \pm 0.05,0.21 \pm 0.05$, $0.35 \pm 0.10$, and $0.28 \pm 0.10 \mathrm{~mm}$ for the sham, control, yam, oestradiol, and genistein group, respectively. The trabecular bone fraction was $0.75 \pm 0.05,0.39 \pm 0.07,0.66 \pm 0.05,0.82 \pm 0.05$, and $0.61 \pm 0.04$ for sham, control, yam, oestradiol, and genistein group, respectively. The trabecular bone fraction of mice fed with yam and genistein diet was almost $88 \%$ and $81 \%$ of that in the sham group, respectively.

\section{Plasma calcium}

The plasma calcium concentrations were $\sim 2.0 \mathrm{mmol} \mathrm{L}^{-1}$ for all, except OVX, groups of mice (Fig. 3). The plasma calcium level of the OVX group was $\sim 92 \%$ of that in the sham group ( $P<0.05$ vs all of the remaining four groups).

\section{Short chain fatty acids in the caecum}

The yam diet significantly increased acetic acid, propionic acid, butyric acid and total fatty acid concentrations in the caecal 


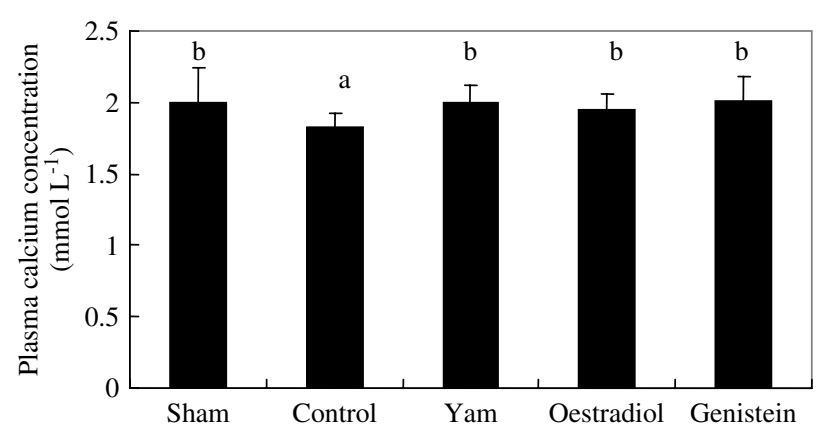

Figure 3. Plasma calcium concentration in the sham group fed the control diet (Sham) and in ovariectomised BALB/C mice fed either the control diet (Control), yam diet (Yam), or a diet supplemented with oestradiol or genistein. Data are expressed as mean \pm SD ( $n=8-11$ animals per group). Different superscript letters denote significant differences across group as analysed by Duncan's multiple test $(P<0.05)$.
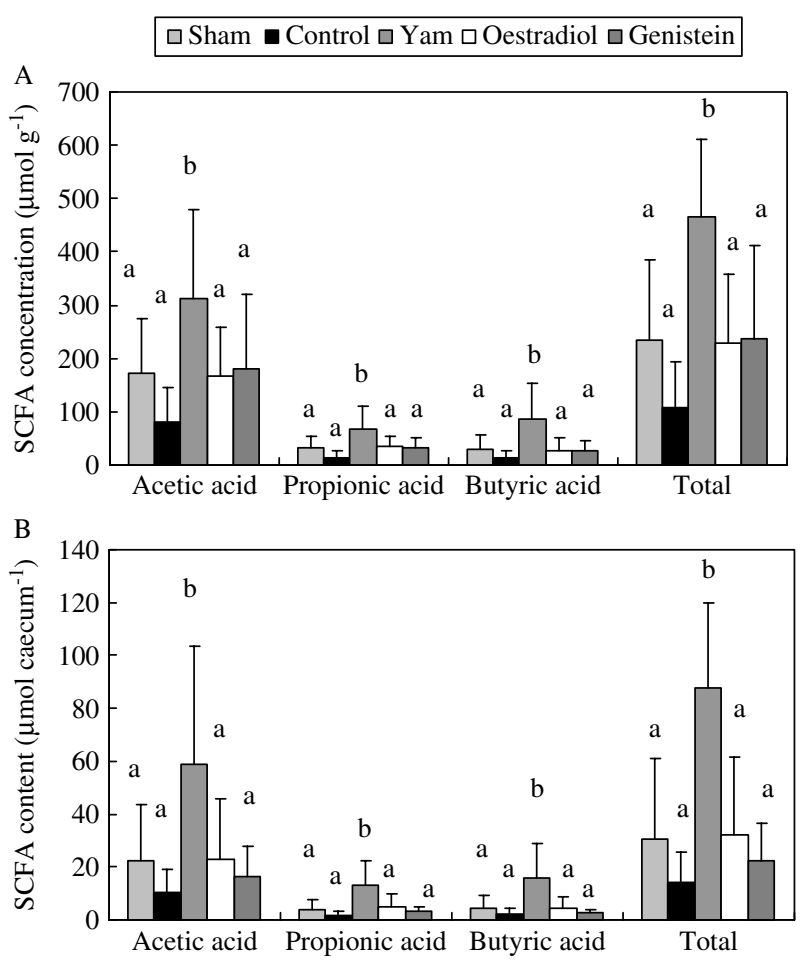

Figure 4. (A) Concentration and (B) amount of short chain fatty acids in caecum in the sham group fed the control diet (Sham) and in ovariectomised BALB/C mice fed either the control diet (Control), yam diet (Yam), or the diet supplemented with oestradiol or genistein. Data are expressed as mean \pm SD ( $n=8-11$ animals per group). Different superscript letters denote significant differences across group as analysed by Duncan's multiple test $(P<0.05)$.

contents as compared to the other diets $(P<0.05$ vs all of the remaining four groups) (Fig. 4A). When the mass of caecal content was taken into account, the yam group still produced the greatest amount of acetic acid, propionic acid, butyric acid and total fatty acid ( $P<0.05$ vs all of the remaining four groups) (Fig. 4B).

\section{Correlation between caecal total SCFA content and bone calcium content, or plasma calcium level}

The correlation coefficient between caecal SCFA content (mmol) and femur calcium content (mg), lumbar calcium content (mg) and plasma calcium level $\left(\mathrm{mmol} \mathrm{L}^{-1}\right)$ was $0.07(P>0.05), 0.04$ $(P>0.05)$, and $0.29(P>0.05)$, respectively.

\section{DISCUSSION}

Poulsen and Kruger ${ }^{11}$ recently summarised the phytoestrogen intervention animal studies and showed that most (90\%) studies used rats, and only few studies used mice as the model. The OVX $\mathrm{BALB} / \mathrm{c}$ mice model was first established in this study and we found it mimicked changes in bone metabolism observed in OVX rat ${ }^{22}$ as well as in human postmenopausal osteoporosis; that is, the BMD of OVX mice was apparently lowered compared to that of the sham-operated mice. This mouse model may offer another option to demonstrate the activity of phytoestrogenic compounds.

The present study showed that TNG yam and genistein diets prevented OVX-induced bone loss, but they did not exert oestrogenic activity on preventing the uterine atrophy. This organspecific action of TNG yam on postmenopausal syndromes implied that TNG yam may act similarly to genistein as a selective oestrogen receptor modulator (SERM). ${ }^{8}$ This SERM role of TNG yam was supported by the study by Cheng et al. ${ }^{5}$ which demonstrates three out of five TNG yam phytoestrogenic compounds ( $\gamma$-tocopherol9, coenzyme Q9 and 1-feruloylglycerol) are stronger agonists for oestrogen receptor- $\beta$, while the other two compounds ( $\alpha$ tocopherol and hydro-Q9 chromene) exert similar activity for oestrogen receptor- $\alpha$ and oestrogen receptor- $\beta$, based on the ligand-dependent transactivation assay of oestrogen receptors. We speculate that the phytoestrogens of TNG yam might act similarly to soy isoflavones that have been shown to inhibit parathyroid hormone-induced bone resorption ${ }^{9}$ and osteoclast activity. ${ }^{10}$

Although the yam diet had a strong protective effect on BMD in either the femur or lumbar bone, it did not seem to fully protect the loss of ash content. The bone density $\left(\mathrm{g} \mathrm{cm}^{-2}\right)$ measured by dual-energy $\mathrm{X}$-ray absorptiometry reflects the overall density of all bone tissues, including both organic and inorganic matter, while ash content was composed of only inorganic matter. Therefore, our study suggested that the TNG yam diet maintained both the inorganic matter and collagen content of the bone.

The role of dietary protein intake on bone mass is not conclusive. Acidosis caused by high-protein intake is considered potentially detrimental for bone health in humans ${ }^{23,24}$ and rats, ${ }^{25}$ while other reports have emphasised that high protein intake benefits bone health. ${ }^{26-28}$ Since the protein content of TNG yam is greater than that of corn starch, we previously tested different protein levels of TNG diet in a pilot study. We found that when mice were fed an isoprotein yam diet in which casein was partially replaced by yam protein in order to provide equal amount of total protein as the control diet, the growth of mice was hampered as compared to the control group. However, this adverse effect was not observed when mice were fed a high-protein yam diet in which casein was maintained at the same level as the control diet in addition to the protein derived from yam. This observation was not surprising as Chen et al. ${ }^{29}$ have reported that diets consisting of greater than $250 \mathrm{~g} \mathrm{~kg}^{-1}$ raw TNG yam depressed the apparent absorption of dietary protein and lipid. Although the yam used in this study was cooked, it might still reduce the bioavailability of protein to some degree. Based on the role of protein on the bone structure ${ }^{26-28}$ and the growth effect of casein found in the pilot study, we decided to formulate a high-protein TNG diet for this study. This high-protein TNG diet was proven not to be a confounding factor 
in the bone protection effect of the yam diet, but may be beneficial in maintaining organic matter in bones.

The calcium intake and bioavailability of calcium could affect the bone mass. Therefore, it is essential to ensure similar calcium intake among different groups of mice. Although complete replacement of corn starch with TNG yam led to a slightly lower calcium content than in the control diet, daily calcium intake was not significantly different among groups when feed intake was taken into account. However, the bioavailability of dietary calcium was not examined in this study. Although we originally proposed that the TNG diet might increase the absorption of dietary calcium through fermentation products that increase the solubility of calcium, ${ }^{12,13}$ no significant correlation was found between caecal SCFA content and bone or plasma calcium levels. Since homeostasis of the plasma calcium level is tightly regulated, the potential increase in calcium absorption by TNG fermentation may not result in an increased plasma calcium level as the dietary calcium in the diet was sufficient $\left(>5 \mathrm{~g} \mathrm{~kg}^{-1}\right)$. Therefore, TNG yam may not prevent OVX-induced bone loss via modulation of calcium bioavailability, but mainly by direct phytoestrogenic effects.

\section{CONCLUSION}

The present study showed that, in OVX BALB/c mice, the TNG yam diet preserved BMD of femur and lumbar bone and plasma calcium concentration, but was completely ineffective in maintaining uterine mass. This bone-protective effect was likely to be mediated by phytoestrogenic compounds.

\section{ACKNOWLEDGEMENTS}

This study was supported by grants from the National Science Council (NSC 92-2321-B-002-011; 93-2321-B-002-012).

\section{REFERENCES}

1 Liu SY, Chang TW, Lin YK, Chen SF, Wang JY and Zu GL, et al, Studies on the varietal characters, production potential, phytochemical properties, and antioxidant effect of Dioscorea spp. J Agric Res China 48:1-22 (1999).

2 Lia HL, Dung SM, Liu SY and Hsu PW, Identification of herb medicine in Dioscorea. Herb Food Anal 7:313-325 (1999).

3 Wang $\mathrm{CH}$, Tsai $\mathrm{CH}$, Lin HJ, Wang TC and Chen HL, Uncooked Taiwanese yam (Dioscorea alata L. cv. Tainung No. 2) beneficially modulated the large bowel function and faecal microflora in BLAB/c mcie. J Sci Food Agric 87:1374-1380 (2007).

4 Wu WH, Liu LY, Chung CJ, Jou HJ and Wang TA, Estrogenic effect of yam ingestion in healthy postmenopausal women. J Am Coll Nutr 24:235-243 (2005).

5 Cheng WY, Kuo YH and Huang C-J, Isolation and identification of novel estrogenic compounds in yam tuber (Dioscorea alata Cv. Tainung No. 2). J Agric Food Chem 55:7350-7358 (2007).

6 Arjmandi $\mathrm{BH}$, The role of phytoestrogens in the prevention and treatment of osteoporosis in ovarian hormone deficiency. J Am Coll Nutr 20:398S-402S (2001).

7 Johannes CB, Crawford SL, Posner JG and McKinlay SM, Longitudinal patterns and correlates of hormone replacement therapy use in middle-aged women. Am J Epidemiol 140:439-452 (1994).
8 Morito K, Hirose T, Kinjo J, Hirakawa T, Okawa M and Nohara T, et al, Interaction of phytoestrogens with estrogen receptors alpha and beta. Biol Pharm Bull 24:351-356 (2001).

9 Gao YH and Yamaguchi M, Suppressive effect of genistein on rat bone osteoclasts: involvement of protein kinase inhibition and protein tyrosine phosphatase activation. Int J Mol Med 5:261-267 (2000).

10 Yamaguchi $M$ and Gao YH, Inhibitory effect of genistein on bone resorption in tissue culture. Biochem Pharmacol 55:71-76 (1998).

11 Poulsen R and Kruger M, Soy phytoestrogens: impact on postmenopausal bone loss and mechanisms of action. Nutr Review 66:359-374 (2008).

12 Schulz AG, Van Amelsvoort JM, and Beynen AC, Dietary native resistant starch but not retrograded resistant starch raises magnesium and calcium absorption in rats. J Nutr 123:1724-1731 (1993).

13 Morais MB, Feste A, Miller RG and Lifschitz CH, Effect of resistant and digestible starch on intestinal absorption of calcium, iron, and zinc in infant pigs. Pediatr Res 39:872-876 (1996).

14 Association of Official Analytical Chemists, Official Methods of Analysis, 14th edition. AOAC, Washington, DC (1984).

15 Association of Official Analytical Chemists, Official Methods of Analysis, 17th edition. AOAC, Washington, DC (2000).

16 National Research Council, Guide for the Care and Use of Laboratory Animals. Publication 85-23, Revised. National Institutes of Health, Bethesda, MD (1985).

17 Ward W, Kim S, Chan D and Fonseca D, Serum equol, bone mineral density and biomechanical bone strength differ among four mouse strains. J Nutr Biochem 16:743-749 (2005).

18 Goulet R, Goldstein S, Ciarelli M, Kuhn J, Brown M and Feldkamp L, The relationship between the structural and orthogonal compressive properties of trabecular bone. J Biomech 27:375-389 (1994).

19 Chen HL, Lu YH, Lin JJ and Ko LY, Effects of isomalto-oligosaccharides on bowel functions and indicators of nutritional status in constipated elderly men. J Am Coll Nutr 20:44-49 (2001).

20 Remesy $C$ and Demigne $C$, Determination of volatile fatty acids in plasma after ethanolic extraction. Biochem J 141:85-91 (1974).

21 Ott L, An Introduction to Statistical Methods and Data Analysis, 3rd edition. PWS-Kent Publishing, Boston, MA (1988).

22 Goss PE, Qi S, Cheung AM, Hu H, Mendes M and Pritzker KP, The selective estrogen receptor modulator SCH 57068 prevents bone loss, reduces serum cholesterol and blocks estrogen-induced uterine hypertrophy in ovariectomized rats. J Steroid Biochem Mol Biol 92:79-87 (2004).

23 Feskanich D, Willett WC, Stampfer MJ and ColditzGA, Protein consumption and bone fractures in women. Am J Epidemiol 143:472-479 (1996).

24 Zwart SR, Davis-Street JE, Paddon-Jones D, Ferrando AA, Wolfe RR and Smith SM, Amino acid supplementation alters bone metabolism during simulated weightlessness. J Appl Physio/ 99:134-140 (2005).

25 Amanzadeh J, Gitomer WL, Zerwekh JE, Preisig PA, Moe OW and Pak CY, et al, Effect of high protein diet on stone-forming propensity and bone loss in rats. Kidney Int 64:2142-2149 (2003).

26 Promislow JH, Goodman-Gruen D, Slymen DJ and Barrett-Connor E, Protein consumption and bone mineral density in the elderly: the Rancho Bernardo Study. Am J Epidemiol 155:636-644 (2002).

27 Kerstetter JE, O'Brien KO, Caseria DM, Wall DE and Insogna KL, The impact of dietary protein on calcium absorption and kinetic measures of bone turnover in women. J Clin Endocrinol Metab 90:26-31 (2005).

28 Dawson-Hughes B, Harris SS, Rasmussen H, Song L and Dallal G$E$, Effect of dietary protein supplements on calcium excretion in healthy older men and women. J Clin Endocrinol Metab 89:1169-1173 (2004).

29 Chen HL, Wang CH, Chang CT and Wang TC, Effects of Taiwanese yam (Dioscorea alata L. cv. Tainung No. 2) on the mucosal hydrolase activities and lipid metabolism in Balb/c mice. Nutr Res 23:791-801 (2003). 